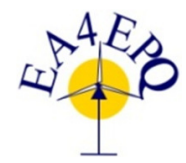

International Conference on Renewable Energies and Power Quality (ICREPQ'13)

Bilbao (Spain), $20^{\text {th }}$ to $22^{\text {th }}$ March, 2013

Renewable Energy and Oover Qualily. Fournal (RE\&PQJ)

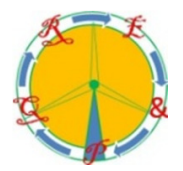

ISSN 2172-038 X, No.11, March 2013

\title{
Effect of Acceptance angle on the design and performance of a heat pipe based compound parabolic collector at Kano, Nigeria
}

\author{
B. Abdullahi ${ }^{1}$, R.K. AL-Dadah ${ }^{1}$ and S. Mahmoud ${ }^{1}$ \\ ${ }^{1}$ School of Mechanical Engineering \\ University of Birmingham \\ Birmingham, United Kingdom, B15-2TT \\ Phone number:+0044 1214143513, e-mail: R.K.Al-Dadah@bham.ac.uk
}

\begin{abstract}
The performance of any solar collector depends on the solar radiation available, its design and orientation. The aim of this work is to develop a compound parabolic solar collector (CPC) and optimize its performance for domestic use under climatic condition of Kano, Nigeria $\left(\Phi=12.05^{\circ} \mathrm{N}\right)$. The acceptance angle plays an important role in determining the solar radiation acceptance of the CPC collector. Therefore this paper investigates the effect of the acceptance angle on the CPC design, solar radiation collection and absorption by the heat pipe receiver installed inside the CPC collector. From the radiation data and the analysis used, this study shows that as the acceptance angle increases, the collector height decreases and the concentration ratio increases.
\end{abstract}

\section{Key words}

CPC, acceptance angle, solar radiation, concentration ratio, collector geometry

\section{Introduction}

The use of solar collectors to harness sun radiation is getting more attention due to the cost of fossil fuel and the environmental pollution caused. Solar energy has great potential in Nigeria especially in the far north (like Kano state) where the radiation available reaches 26.78 $\mathrm{MJ} / \mathrm{m}^{2}$.day $\left(7.44 \mathrm{kWh} / \mathrm{m}^{2}\right.$.day) as shown in Figure 1 . Also Kano has the advantages of high average daylight hours of 12 and high clearness index. Nigerians face serious energy problems for many decades such as regular power outage, lack of electricity access in most rural areas which leads to poor production output and crops wastage. National task force on power has identified that the electricity supply in the country with 150 million people is $3.8 \mathrm{GW}$, which is below the required level. Kano is the most populace state in Nigeria. Therefore, provision of power generators has become an integral part of planning for any manufacturer and able households. Figure 1 shows the global radiation on horizontal surface of Kano state according to the Nigerian meteorological Agency [1].

Also despite the efforts made on awareness of the use of solar technology to supplement the conventional sources, yet such technology did not reach most of the households due to cost/efficiency of the PV systems and the financial status of the citizens. It is hoped that developing an efficient and affordable solar thermal collector for domestic electricity supply (and for other applications) may help in solving most of the problems stated. Collectors can be categorised based on their motion, concentration, operational temperature, e.t.c. and classified as concentrating or non-concentrating. Different types of collectors with their concentration ratios, mode of operation and operational temperature ranges are shown in table 1.

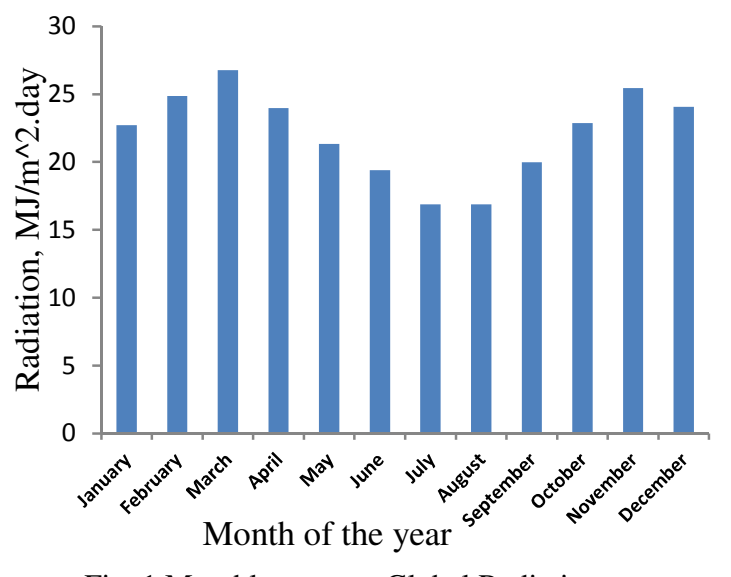

Fig. 1 Monthly average Global Radiation on horizontal surface $\left(\mathrm{MJ} / \mathrm{m}^{\wedge} 2\right.$ day) 
Table 1: Different types of collectors and their temperature range [2]

\begin{tabular}{|c|c|c|c|c|}
\hline $\begin{array}{c}\text { Motio } \\
\mathrm{n}\end{array}$ & Collector type & $\begin{array}{l}\text { Absorber } \\
\text { type }\end{array}$ & $\begin{array}{l}\text { Concen } \\
\text { tration } \\
\text { ratio }\end{array}$ & $\begin{array}{l}\text { Temperat } \\
\text { ure range } \\
\left({ }^{\circ} \mathrm{C}\right)\end{array}$ \\
\hline \multirow[t]{3}{*}{$\begin{array}{l}\text { Statio } \\
\text { nary }\end{array}$} & $\begin{array}{c}\text { Flat-plate } \\
\text { collector (FPC) }\end{array}$ & Flat & 1 & $30-80$ \\
\hline & $\begin{array}{l}\text { Evacuated tube } \\
\text { collector (ETC) }\end{array}$ & Flat & 1 & $50-200$ \\
\hline & \multirow{2}{*}{$\begin{array}{c}\text { Compound } \\
\text { Parabolic } \\
\text { Collector }(\mathrm{CPC})\end{array}$} & \multirow[t]{2}{*}{ Tubular } & $1-5$ & $60-240$ \\
\hline \multirow{4}{*}{$\begin{array}{c}\text { Singl } \\
\text { e-axis } \\
\text { tracki } \\
\text { ng }\end{array}$} & & & $5-15$ & $60-300$ \\
\hline & $\begin{array}{l}\text { Linear Fresnel } \\
\text { reflector (LFR) }\end{array}$ & Tubular & $10-40$ & $60-250$ \\
\hline & $\begin{array}{c}\text { Cylindrical } \\
\text { trough collector } \\
\text { (CTC) }\end{array}$ & Tubular & $15-50$ & $60-300$ \\
\hline & $\begin{array}{l}\text { Parabolic trough } \\
\text { collector (PTC) }\end{array}$ & Tubular & $10-85$ & $60-400$ \\
\hline \multirow{2}{*}{$\begin{array}{l}\text { Two- } \\
\text { axis } \\
\text { tracki } \\
\text { ng }\end{array}$} & $\begin{array}{l}\text { Parabolic dish } \\
\text { reflector (PDR) }\end{array}$ & Point & $\begin{array}{l}600- \\
2000 \\
\end{array}$ & $100-1500$ \\
\hline & $\begin{array}{c}\text { Heliostat field } \\
\text { collector (HFC) }\end{array}$ & Point & $\begin{array}{l}300- \\
1500\end{array}$ & $150-2000$ \\
\hline
\end{tabular}

Compound parabolic collectors (CPCs) are non-imaging concentrators which can accept and reflect incoming radiation to the absorber surface located at the bottom of the collector. CPCs are suitable for domestic applications in Kano due to their advantages over other concentrating collectors, climatic conditions of the area and the economy of the people. Among these advantages are possessing properties of both flat plate and concentrating collectors, high optical and quantum efficiencies, and minimum errors of alignment. The CPCs can be equipped with heat pipes that effectively absorb the concentrated solar radiation and provide the heat input for an organic Rankine cycle power plant.

\section{Mathematical Modelling of Solar Radiation of Kano}

Figure 1 shows the monthly distribution of the global solar radiation on a horizontal surface, $\bar{H}$ for Kano state [1]. Using this data and the formulae developed by Rabl, 1985 and others, the hourly diffuse $I_{d}$, hemispherical $I_{h}$ and beam $\mathrm{I}_{\mathrm{b}}$ solar radiation on horizontal and inclined surfaces were obtained as follow [3]:

$I_{d}=r_{d}\left(w, w_{s}\right) \overline{H_{d}}$

where

$r_{d}(w, w)=\frac{\pi}{\tau_{d a y}} \frac{\cos w-\cos w_{s}}{\sin w_{s}-\left(\pi w_{s} / 180^{\circ}\right) \cos w_{s}}$

$I_{h}=r_{h}\left(w, w_{s}\right) \bar{H}$

where $r_{h}\left(w, w_{s}\right)=(a+b \cos w) r_{d}\left(w, w_{s}\right)$

and

$I_{b}=\frac{I_{h}-I_{d}}{\cos \theta_{z}}$ and $\tau_{\text {day }}=$ length of the day $=24$ hrs. and hour angle,

$w=\frac{360^{\circ}}{\tau_{\text {day }}} t$

$w_{s}$ is the sunset hour angle given by [3];

$w_{s}=-\tan \phi \tan \delta$

The coefficients a and $\mathrm{b}$ are given by;

$a=0.4090+0.5016 \operatorname{Sin}\left(w_{s}-60^{\circ}\right)$

$b=0.6609-0.4767 \operatorname{Sin}\left(w_{s}-60^{\circ}\right)$

The $\overline{H_{d}}$, is the monthly average diffuse radiation, obtained from [4]:

$\frac{\overline{H_{d}}}{\bar{H}}=0.775+0.00606\left(w_{s}-90\right)$

$-\left[0.505+0.00455\left(w_{s}-90\right)\right] \cos \left(115 \overline{K_{T}}-103\right)$

The monthly average clearness index, $\overline{K_{T}}$, is given by $\overline{\mathrm{K}_{\mathrm{T}}}=\frac{\overline{\mathrm{H}}}{\overline{\mathrm{H}_{o}}}$

The monthly average extra-terrestrial radiation, $\overline{H_{o}}$ in $n t h$ day of the year, is [4]:

$\overline{H_{o}}=\frac{24 X 3600 G_{s c}}{\pi}\left(1+0.033 \cos \frac{360 n}{365}\right)$

$X\left(\cos \phi \cos \delta \sin \omega_{s}+\frac{\pi \omega_{s}}{180} \sin \phi \sin \delta\right)$

$G_{s c}$ is the solar constant (taken as $1367 \mathrm{~W} / \mathrm{m}^{2}$ ) and $\delta$ is solar declination;

$\delta=\left(23.45^{\circ}\right) \sin \left[360^{\circ}(284+n) / 365\right]$

\section{Modelling of Heat Pipe and CPC Geometry}

The CPC for this work is intended to use an evacuated heat pipe receiver to enhance heat transfer and minimise heat losses, as shown schematically in Figure 2. The hourly radiation accepted by the CPC is given by [3]:

$I=I_{b} \cos \theta+\frac{I_{d}}{C}$

Where $\theta$ is the incident angle given by [4]: $\operatorname{Cos} \theta=\operatorname{Cos}(\phi-\beta) \operatorname{Cos} \delta \operatorname{Cos} \omega+\operatorname{Sin}(\phi-\beta) \operatorname{Sin} \delta$

The amount of radiation absorbed by the heat pipe receiver of the CPC can be obtained [2]:

$S=G_{t} \tau_{\text {cover }} \tau_{C P C} \alpha_{r} \gamma$

where $\gamma=1-\left(1-\frac{1}{C}\right) \frac{G_{D}}{G_{t}}$ 


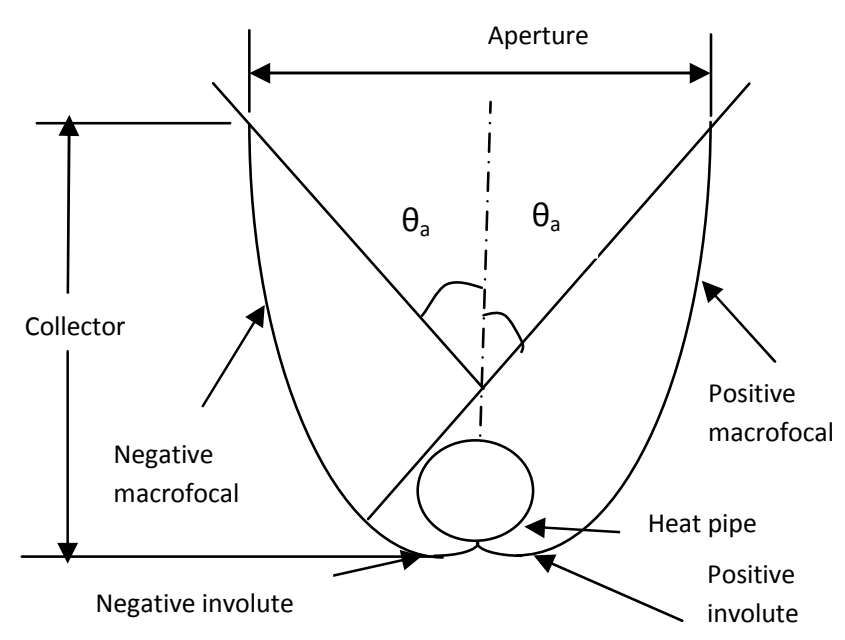

Fig. 2 CPC with tubular receiver

In Figure 2, $\theta_{\mathrm{a}}$ is the half acceptance angle and is related to the concentration ratio, $\mathrm{C}$ as [3], [4]:

$$
C=\frac{A_{a}}{A_{r}}=\frac{1}{\operatorname{Sin} \theta_{a}}
$$

The geometries of a CPC with tubular receiver can be generated in terms of the half acceptance angle and the receiver radius, $r$ as [5]:

For involute section;

$$
\begin{aligned}
x & =r( \pm \phi \operatorname{Cos} \phi \pm \operatorname{Sin} \phi) \\
y & =r(-\operatorname{Cos} \phi-\phi \operatorname{Sin} \phi) \\
& \quad-\left(\frac{\pi}{2}+\theta c\right) \subseteq \phi \subseteq 0
\end{aligned}
$$

And for macro- focal parabola section;

$$
\begin{aligned}
& x=\frac{r}{\operatorname{Cos} \phi-1}\left[\begin{array}{l} 
\pm \operatorname{Cos} \theta a \pm \operatorname{Cos}(\phi-\theta a) \pm \\
(2 \hbar-\phi+2 \theta a) \operatorname{Sin}(\phi-\theta a)
\end{array}\right] \\
& y=\frac{r}{\operatorname{Cos} \phi-1}\left[\begin{array}{l}
(-2 \lambda+\phi-2 \theta a) X \operatorname{Cos}(\phi-\theta a) \\
-\operatorname{Sin}(\phi-\theta a)-\operatorname{Sin} \theta a
\end{array}\right]
\end{aligned}
$$

Where $2 \theta a \subseteq \phi \subseteq \lambda$

Figure 3 schematically shows the principle of operation of the receiver heat pipe. It consists of three sections; the evaporator where heat is absorbed to evaporate a working fluid, condenser where heat is rejected and the adiabatic section. The working fluid (in this case water) evaporates by the solar radiation collected and the heat rejected at the condenser is used by the relevant application. On the internal surface of the heat pipe, a wick is used to facilitate the flow of the condensate from the condenser to the evaporator.

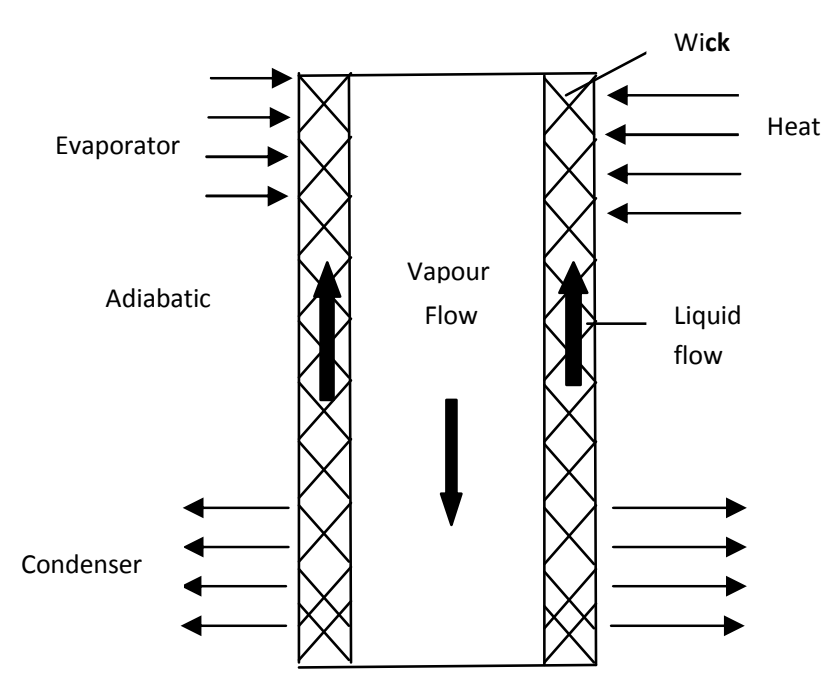

Fig. 3 Heat pipe operation

Figure 4 shows the thermal resistances model of the heat pipe where $R_{1}, R_{2}$ and $R_{3}$ are wick, wall and external resistances on the evaporator side as given in Table 2. $R_{4}$, $\mathrm{R}_{5}$ and $\mathrm{R}_{6}$ are the vapour- liquid interface on both side and the wall and wick axial resistances which are mostly neglected [6], [7]. $\mathrm{R}_{7}, \mathrm{R}_{8}$ and $\mathrm{R} 9$ are the wick, wall and external resistances on the condenser side and are calculated in the same way as those in the evaporator side. $\mathrm{R}_{10}$ and $\mathrm{R}_{11}$ are the vapour- liquid interface on both side and the wall and wick axial resistances which are mostly neglected. Three heat pipes of $12.5 \mathrm{~mm}, 22.5 \mathrm{~mm}$ and $25.0 \mathrm{~mm}$ radii were mathematically modelled using heat resistance method (Figure 4) to find the length at which the pipe meet the required output.

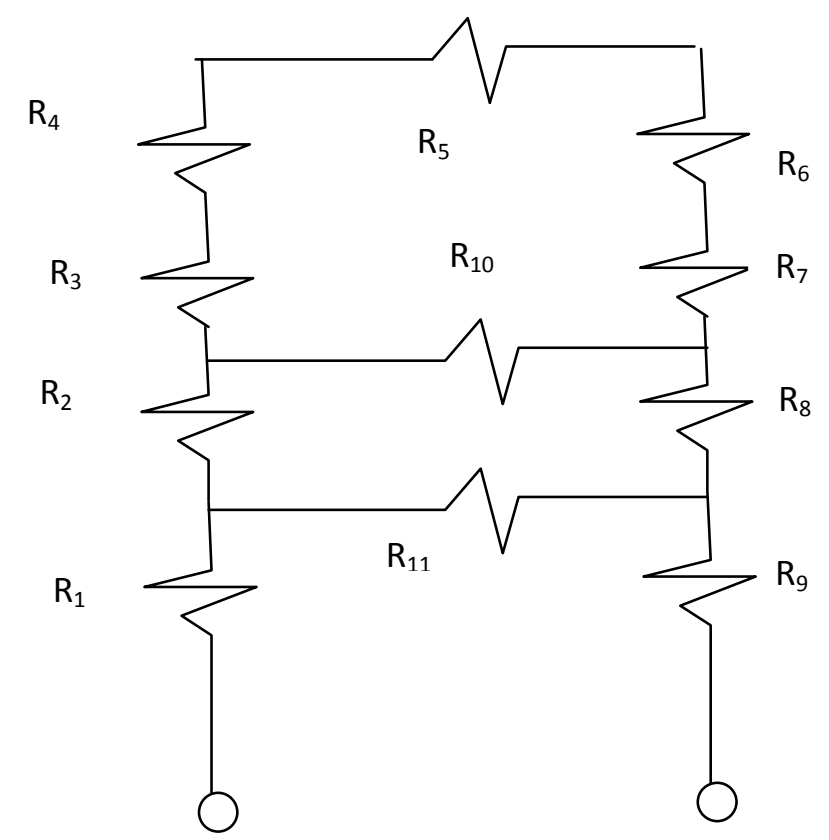

Fig. 4 Heat pipe thermal resistance 
Table 2 Heat Pipe thermal resistances [7], [8].

\begin{tabular}{|c|c|c|}
\hline RESISTANCE & EQUATION & DEFINITIONS \\
\hline $\begin{array}{l}\text { External resistance on evaporator } \\
\text { side, } \mathrm{R}_{1}\end{array}$ & $R_{1}=1 / h_{e} S_{e}$ & $\begin{array}{c}\mathrm{h}_{\mathrm{e}}=\text { heat transfer on evaporator side and } \mathrm{S}_{\mathrm{c}} \\
=\text { surface area of evaporator }\end{array}$ \\
\hline Evaporator wall resistance, $\mathrm{R}_{2}$ & $R_{2}=$ & $\begin{array}{c}d_{t u b e} \text { and } d_{w o}=\text { tube } \& \text { wick diameter } \\
\text { respectively } \\
\mathrm{K}=\text { thermal conductivity \& } l_{e}=\text { effective } \\
\text { length }\end{array}$ \\
\hline Wick resistance, $\mathrm{R}_{3}$ & $R_{3}={ }^{\operatorname{In}(d)}$ & $\begin{array}{c}d_{v}=\text { vapour diameter } \\
K_{\text {eff }}=\text { effective thermal conductivity }\end{array}$ \\
\hline $\begin{array}{l}\text { Effective thermal conductivity of } \\
\text { the wick, } K_{w}\end{array}$ & $K_{w}=K_{s}\left[\frac{2+K_{l} / K}{2+K_{l} / K}\right.$ & $\begin{array}{l}K_{l} \text { and } K_{s} \text { are thermal conductivity of the } \\
\text { liquid and solid respectively. } \\
\varepsilon=\text { porosity of the wick }\end{array}$ \\
\hline
\end{tabular}

Table 3 Characteristics of the CPCs generated.

\begin{tabular}{|c|c|c|c|c|c|}
\hline $\mathrm{s} / \mathrm{n}$ & Receiver radius, $\mathrm{r}_{\mathrm{ro}}(\mathrm{mm})$ & Geometric Parameters & Full $\left(30^{\circ}\right)$ & Full $\left(20^{\circ}\right)$ & Full $\left(15^{\circ}\right)$ \\
\hline \multirow{4}{*}{1} & \multirow{4}{*}{12.5} & Collector height (mm) & 180.66 & 371.617 & 634.171 \\
\hline & & Aperture width (mm) & 157.08 & 229.64 & 303.45 \\
\hline & & Concentration ratio & 2 & 2.92 & 3.86 \\
\hline & & Height to aperture ratio & 1.15 & 1.62 & 2.09 \\
\hline \multirow{4}{*}{2} & \multirow{4}{*}{22.5} & Collector height $(\mathrm{mm})$ & 325.796 & 668.91 & 1141.51 \\
\hline & & Aperture width (mm) & 282.74 & 413.34 & 546.22 \\
\hline & & Concentration ratio & 2 & 2.92 & 3.86 \\
\hline & & Height to aperture ratio & 1.15 & 1.62 & 2.09 \\
\hline \multirow{4}{*}{3} & \multirow{4}{*}{25.0} & Collector height $(\mathrm{mm})$ & 361.329 & 743.234 & 1268.34 \\
\hline & & Aperture width (mm) & 314.16 & 459.27 & 606.91 \\
\hline & & Concentration ratio & 2 & 2.92 & 3.86 \\
\hline & & Height to aperture ratio & 1.15 & 1.62 & 2.09 \\
\hline
\end{tabular}

\subsection{Results and Discussion}

The acceptance angle of CPC which is the maximum angle at which in coming radiation is captured by the collector, is vital in the determination of the rays acceptance and rejection. A parametric study was carried out to investigate the effect of acceptance angle on the CPC geometry and performance at various heat pipe receiver radii. For this work, three different half acceptance angles were considered; $15^{\circ}, 20^{\circ}$ and $30^{\circ}$, receiver radii of $12.5 \mathrm{~mm}, 22.5 \mathrm{~mm}$ and $25.0 \mathrm{~mm}$, receiver absorptivity of 0.93 , cover transmissivity of 0.9 and reflectivity of 0.98 using a slope angle $(\beta)$ equals to the latitude angle ( $\Phi)$ of Kano.

Using the modelling described in sections 2 and 3, various geometries of CPC were generated as shown in Figure 5 and Table 3 . Table 3 shows the characteristics of the collectors generated from the model in terms of aperture width, collector height, concentration ratio and height to aperture ratio at different acceptance angles and receiver radii. Figures $6 \mathrm{a}, \mathrm{b}$ and $\mathrm{c}$ show the variation of CPC height, width and concentration ratio with the receiver radii at different acceptance angles respectively.
From Figure 6, it can be deduced that the height of the collector, aperture width and height to aperture ratio increase as the acceptance angle decreases. These show that for a large acceptance angle, the size of the collector tends to be small but with wide area of accepting solar radiation. Also, the height and aperture width increase as the receiver radius increases. Finally, the concentration ratio increases as the acceptance angle decreases. So CPC with wide acceptance angle capture more radiation but with small concentration ratio compared to the small angle.

Figures 7 and 8 show the hourly radiation collection and absorption of the CPCs shown in Figure 5. From these figures, it can be seen that more radiation is collected and absorbed when large acceptance angle is used. This is due to the wide area of accepting the radiation especially the diffuse component. Also this is in accordance with equation 12 , where the acceptance of diffuse component of the radiation is affected by the concentration ratio.

Based on the sensitivity test conducted using one-factorat-a-time (OAT/OFAT) approach [ 9], the impact of the input parameters such as material properties, radiation 
data, acceptance angle and receiver radius, were studied on the output (Table 4).

Table 4 Variation of output within the range of the inputs

\begin{tabular}{|l|l|l|l|}
\hline S/N & Input parameter & Range & $\begin{array}{l}\% \text { Variation on } \\
\text { the absorbed } \\
\text { radiation }\end{array}$ \\
\hline 1 & Absorptivity & $0.92-0.94$ & \pm 1 \\
\hline 2 & Transmissivity & $0.85-0.97$ & \pm 6 \\
\hline 3 & Reflectivity & $0.92-0.98$ & \pm 4 \\
\hline 4 & $\begin{array}{l}\text { Solar radiation } \\
\text { data }\end{array}$ & $\begin{array}{l}2006-2008 \\
( \pm 1.8 \%)\end{array}$ & \pm 2.3 \\
\hline 5 & Solar constant & $1353-1367$ & \pm 0.000012 \\
\hline
\end{tabular}

It is clear from Table 4 that variation of material properties such as transmissivity and reflectivity have the most impact on the absorbed radiation of the CPC which ranged from $\pm 4 \%$ to $\pm 6 \%$ respectively.

The model utilized the value of solar constant of 1367 $\mathrm{W} / \mathrm{m}^{2}$ (with uncertainty of $\pm 1 \%$ [4]). The variation of the monthly global radiation due to the use of other values such as $1353 \mathrm{~W} / \mathrm{m}^{2}$ (uncertainty of $\pm 1.5 \%$ [4]) and $1373 \mathrm{~W} / \mathrm{m}^{2}$ (uncertainty of 1 to $2 \%$ [4]) was found to be very negligible of the order of $10^{-5}$ (Table 4 ).

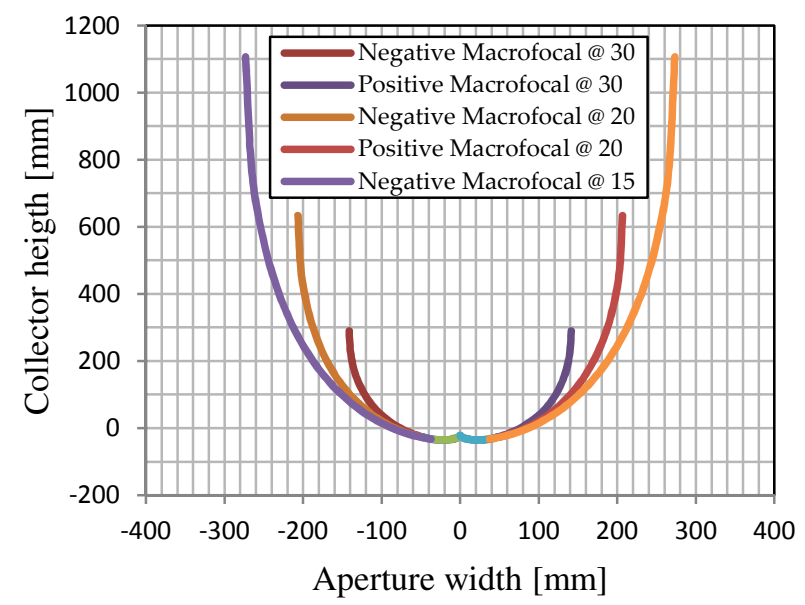

Fig. 5 CPC Profiles generated at different half acceptance angles

All the above results were produced using mean day of the month, defined as day having its extraterrestrial radiation closest to the monthly average, e.g. for Jan is $17^{\text {th }}$, June is $11^{\text {th }}$ [4] e.t.c. The effect of using average day defined as the daily average radiation, on the monthly average radiation was investigated, and results shown in Figure 9. From this figure the difference between those approaches is in the order of $10^{-4}$ which indicates using either the mean or the average day for such analysis yields the same results.

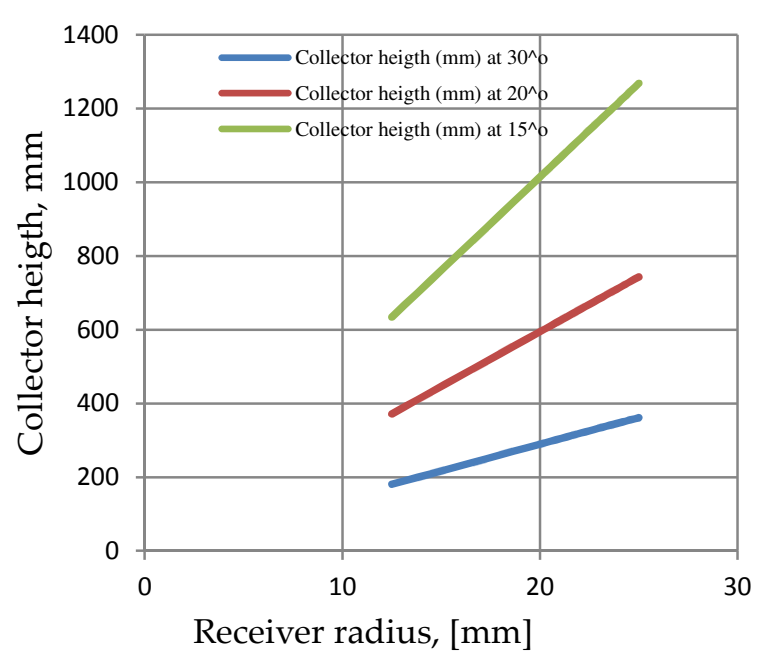

Fig. 6a variations of collector height with half acceptance angles at different receiver radii

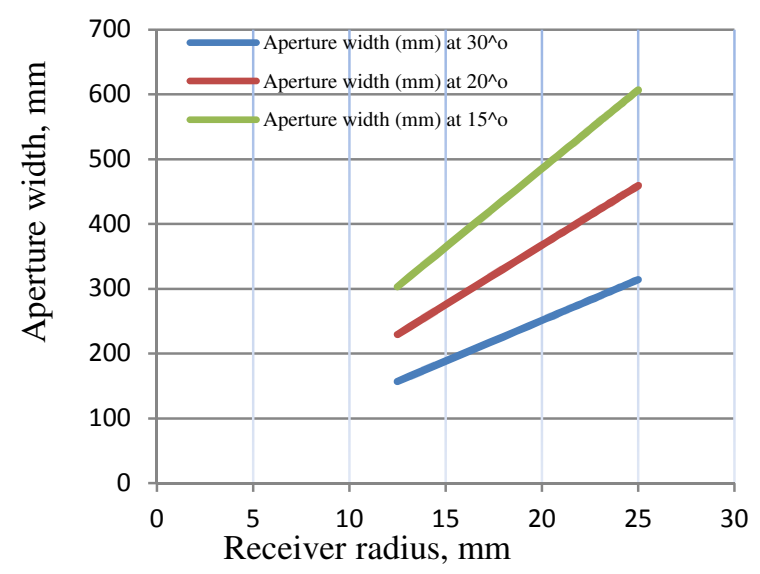

Fig. $6 \mathrm{~b}$ Variation of aperture width with half acceptance angle at different receiver radii

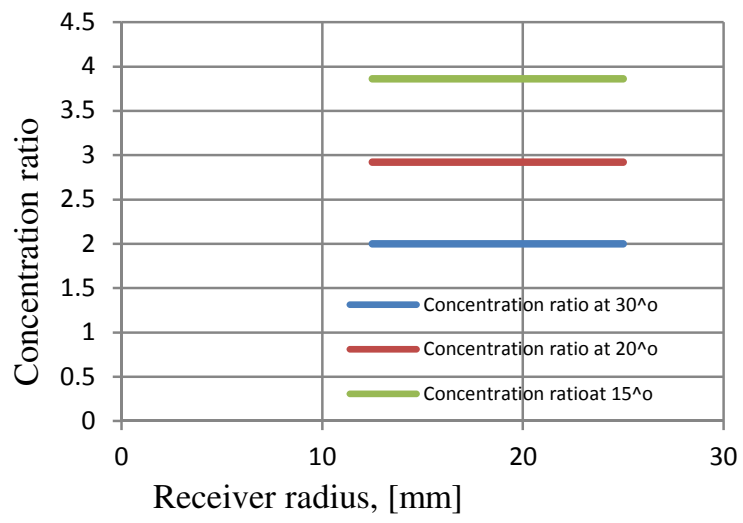

Fig. $6 c$ Concentration ratio at different receiver radius 


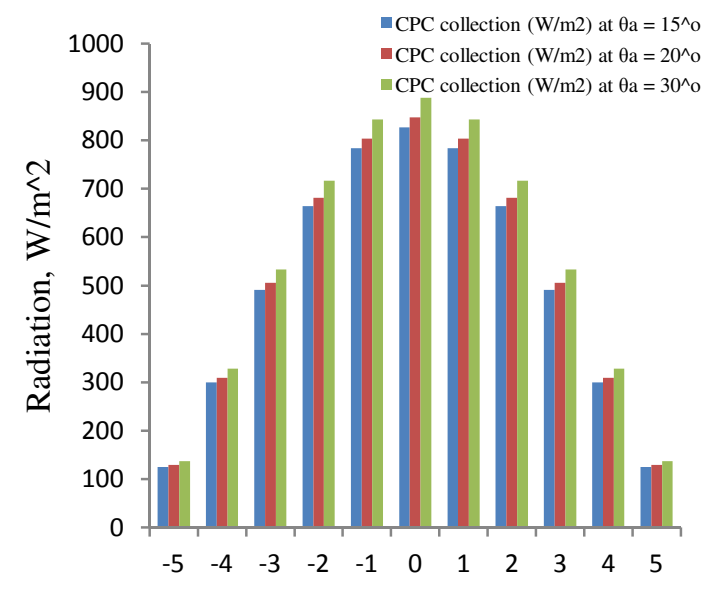

Fig. 7 Hourly CPC Solar time, $t$ different acceptance angles

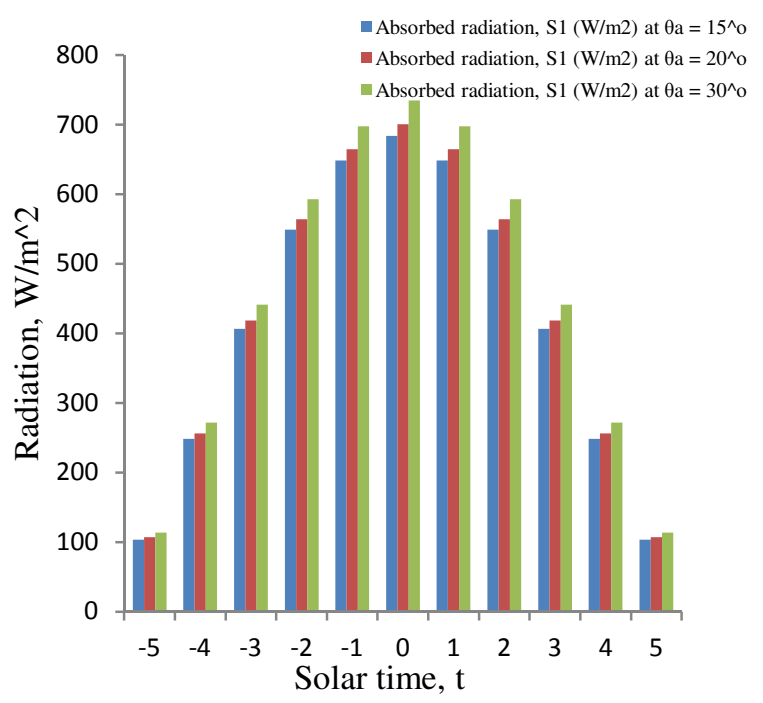

Fig. 8 CPC absorption at different acceptance angles

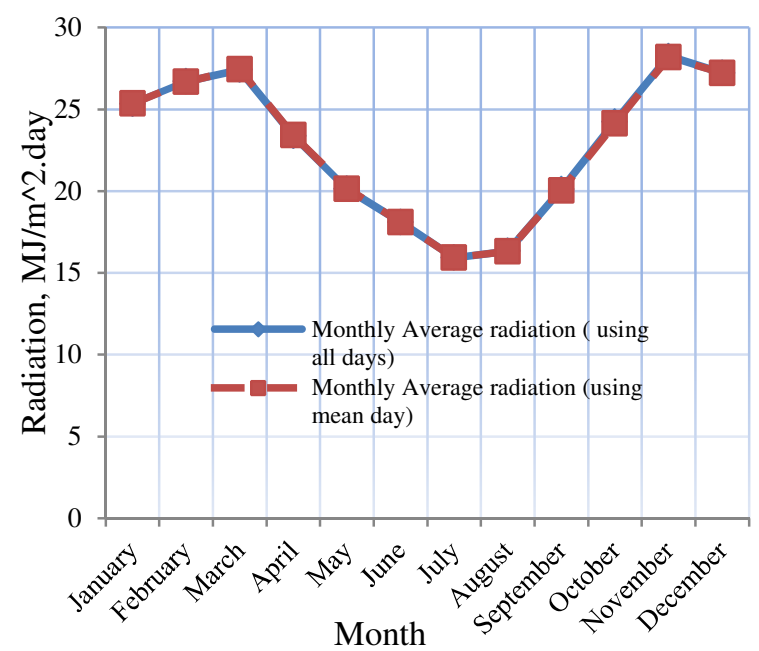

Fig. 9 Monthly average radiation on sloped surface for mean day and all days average.

\subsection{Conclusions}

The acceptance angle of the investigated symmetric parabolic collector has influence on its geometries, concentration ratio, radiation collection and absorption. Although there is small improvement in the radiation collection and absorption, but there is a significant decrease in the collector size/material. As the half acceptance angle increased from $15^{\circ}$ to $30^{\circ}$, a reduction of $50 \%$ and $71 \%$ in terms of width and height was achieved, but the concentration ratio decreased from 4 to 2. However, the values of these improvements may be influenced by the distribution of beam and diffuse radiation components in the area at a particular time of the year. Also the receiver radius plays a vital role in the design of the collector geometry at a certain acceptance angle, while the concentration ratio is not sensitive to the receiver radius.

\section{References}

1. Nigerian Meteorological Agency, corporate office headquarters, Maitama, Abuja.

2. Kalogirous, S. A., Solar Energy Engineering Process and Systems, Elsevier (2009).

3. Rabl A., Active Solar Collectors and their Applications, Oxford University Press, New York Oxford, (1985) ISBN 0-19-503546-1.

4. Duffie J. A. and Beckman W. A. , 1991 Solar Engineering of thermal Processes, A wiley Interscience Publication, John Wiley and sons, Inc. Second edition.

5. Chaves, 2008, Introduction to Nonimaging Optics, CRC Press Taylor and Francis Group.

6. Peterson G. P. An introduction to heat pipes, modelling, testing and Applications, A wileyInterscience Publication.

7. Esdu, 1979, Esdu series on heat transfer, citing "heat pipes- properties of common small- pore wicks. Esdu 79013, Esdu International Plc, London, 1979.

8. Reay D. and Kew P. 2006, Heat pipe theory, design and Application, $5^{\text {th }}$ edition, Butterworth- Heinemann, imprint of Elsevier, USA.

9. Deniel D. Frey, Fredrik E., Edward M. G. A role for "One- factor- at -a- time" experimentation in parameter design, Research in Engineering design 14 (2003). 